\title{
Adaptive mechanisms of a mouse locomotor muscles "m.soleus" and "m.edl" the conditions of the allergic modification of the organism
}

\author{
Albert M. Farkhutdinov, Alexander Y. Teplov, Vladimir I. Torshin*, Elena B. Yakunina, \\ Victor A. Moroz, Olga V. Mankaeva, Zarina V. Bakaeva, Yuri P. Starshinov \\ Received: June 22, 2020. Revised: September 30, 2020. Accepted: October 12, 2020. \\ Published: October 19, 2020.
}

\begin{abstract}
The relevance of the problem discussed in the article is connected to the fact that mandatory athletes' vaccination before competitions leads to the change in the function of the muscular system, the mechanisms of which have not yet been fully clarified. The purpose of the article is to determine the mechanism of a mouse skeletal muscles adaptation (SM) ("fast" (in case of m.edl) and "slow" (in case of m.soleus) in case of allergic alteration. The following research methods were used in the presented work: registration of the constrictive function of the abovementioned muscles in vitro to the humoral constriction initiators (carbacholinum and KCI) and determination of malonyldialdehyde (MDA) level in them, just as the indicators of the oxidant and antioxidant equilibrium. It has been demonstrated that the change in the "slow" muscle strength correlates with the MDA level dynamics, evidently, reflects the adaptation processes during the allergic modification. "Fast"
\end{abstract}

A.Y. Teplov, grand doctor (grand $\mathrm{PhD}$ ) of biological sciences, associate professor, Department of General Pathology, Kazan State Medical University, Kazan, 420015, Russian Federation. E-mail: AlikTeplov@mail.ru, ORCID ID 0000-0003-4753-1792(first corresponding author to provide phone: 79046657830; e-mail: AlikTeplov@mail.ru).

A.M. Farkhutdinov, candidate (PhD) of medical sciences, associate professor, Department of General Pathology of Kazan State Medical University, Kazan, 420015, Russian Federation, e-mail: amfarkhutdinov@gmail.com, ORCID ID 0000-0001-6309-7098

V.I. Torshin*, grand doctor (grand $\mathrm{PhD}$ ) of biological sciences, professor, Honorary Worker of Higher Professional Education of the Russian Federation, Department of normal physiology Medical Institute Peoples' Friendship University of Russia, Moscow, 117198, Russian federation, email: vtorshin@mail.ru; ORCID ID 0000-0002-3950-8296 (second corresponding author to provide phone: 74954331022; e-mail: vtorshin@mail.ru).

E. B. Yakunina, assistant, Department of normal physiology Medical Institute Peoples' Friendship University of Russia Moscow, 117198, Russian federation, email: dr.yakunina@gmail.com, ID ORCID 0000-0002-79621971

V. A. Moroz, candidate $(\mathrm{PhD})$ of medical sciences, Associate Professor, Department of Anesthesiology and Reanimatology Medical Institute Peoples' Friendship University of Russia, Moscow, 117198, Russia. Email: Doctormoroz@yandex.ru, ORCID ID 0000 -0002-3467-7170

O. V. Mankaeva, candidate (phD) of medical sciences, Senior Lecturer, Department of normal physiology Medical Institute Peoples' Friendship University of Russia, Moscow, 117198, Russia, email: mankaeva_ov@pfur.ru

Z.V. Bakaeva, assistant, Department of normal physiology Medical Institute Peoples' Friendship University of Russia, Moscow, 117198, Russia. E-mail: bakaeva_zv@mail.ru, ID ORCID 0000-0001-7795 -0897

Y.P. Starshinov, candidate $(\mathrm{PhD})$ of medical sciences, senior researcher, associate professor, Department of normal physiology Medical Institute Peoples' Friendship University of Russia, Moscow, 117198, Russia. Email: 1345301@mail.ru, ORCID ID 0000-0002-1836-6209 muscles turn out to be more sustainable to oxidative stress which is most probably achieved by the work of compensatory mechanisms and is expressed in quite minor changes in the MDA dynamics. The article can be used in the search of the new possibilities for the correction of the locomotor muscles function in the conditions of the allergy, and also while the therapeutic impact strategy is determined, taking into account their fiber composition.

Keywords - skeletal muscle, contractive properties, allergy, protein sensibilization, malondialdehyde, carbacholinum, potassium chloride, mouse

\section{INTRODUCTION}

The interest towards the study of pathogenesis of allergic diseases has been high. The change in the muscular system's responsiveness and, in particular, of the transverses stripe muscle flexibility mechanisms in case of allergy have not been researched in detail. The relevance of this problem is determined by the demands of fitness biology and medicine. The facts of protein sensibilization (PS) impact upon the locomotor muscles function during the athletes mandatory vaccination before the competitions. It is evident that during the allergic modification of sceletal muscles (SM) the tissue can not remain insensitive to humoral factors which appear in the organism while the allergic response is forming [1]. We have demonstrated before that PS changes carbacholinum contraction of both "fast" and "slow" SM of a mouse's shin in vitro $[2 ; 3]$. The discovered differences are related to the postsynaptic membrane excitation mechanisms, in which ATP plays the role of a synaptic transmission cofactor. However, not only muscle fiber (MF) membrane excitation processes [4; 5] play certain role in the mechanisms of changing muscles strength, but also the next stages in the work of the electromechanical coupling (EMC) system. We demonstrated earlier the possibility of discovering these stages via registering their contractile ability [6]. Besides, oxidative stress plays a part in the pathogenesis of allergic diseases, with malonyldialdehyde (MDA) being one of the key markers [7; 8].

\section{RESEARCH METHODOLOGY}

Purpose. To study the character of changes in PS conditions: 1) of the contractile function in vitro of a mouse's 
transversal stripe muscles (the "slow" one, m.soleus, and the "fast" one, m.edl ) during its generation by various humoral agents: carbacholinum (CC) and potassium chloride ( $\mathrm{KCl}) ; 2$ ) the content of MDA in the serum and the tissues of the abovementioned muscles; 3) dynamics of a number of indicators, which characterize the condition of the oxidant and antioxidant equilibrium systems in the blood of the intact and the sensibilized mice.

Materials and methods. Experiments were conducted on mice of both genders, with the body mass of 17-22 g. The animals were sensibilized twice by ovalbumin (OA) with aluminium hydrate gel $(2 \mathrm{mkg}$ of the gel dry substance +150 mkg of OA in $0,5 \mathrm{ml}$ of saline solution) parenterally [1]. In our experiment, animals were taken at the sensibilization peak. Mechanomyographic research was conducted on the isolated muscles preparation in isometric conditions.

Experimental procedure: Muscle preparation was placed vertically into the thermostatic basin with the volume of $5 \mathrm{ml}$. One end of the muscle was firmly fixed, the other end was attached to the mechanical activity sensor by a silk thread. The basin was filled with a modified solution KpePSa of the following composition (in mmol): $\mathrm{NaCl}-118,0, \mathrm{KCl}-4,75$, $\mathrm{CaCl} 2-2,5, \mathrm{NaHCO} 3-24,8, \mathrm{KH} 2 \mathrm{PO} 4-1,18$, $\mathrm{MgSO} 4 \cdot 7 \mathrm{H} 2 \mathrm{O}-1,18$, glucose $-11,0, \mathrm{pH} 7,4 \pm 0,1$. Isometric conditions were achieved by stretching the preparation (the muscle) in a basin for 20 minutes with the force of $0,5 \mathrm{~g}$. during the constant perfusion with the solution, at the constant temperature of $260-280 \mathrm{C}$. Contraction was registered with the help of the force sensor. Contractile function was analyzed by the force and the speed of muscles contraction while using $\mathrm{CC}$ and $\mathrm{KCl}$ in submaximal and maximal concentrations. Contraction initiator concentration which will elicit muscular response which comprises $50-80 \%$ of the maximum in terms of force is usually considered submaximal.

Contraction of isolated SM to the concentration of $\mathrm{K}+$ ions is a simple and accessible "test" for studying EMC processes [6]. The ratio of maximal strength of the muscles during its contraction while using $\mathrm{CC}$ to the maximal strengths, developed by muscles when the contraction happens with the use of $\mathrm{KCl}\left(\mathrm{P}_{\mathrm{KX} \max } / \mathrm{P}_{\mathrm{KClmax}}\right)$ gives the possibility to numerically separate the choline-related processes of fiber membrane excitement processes from the following EMC stages.

The quantitative determination of MDA was conducted in the serum and muscles homogenates in the control and nonsensibilized mice. Determination of MDA in the serum was conducted using T.I. Rakhmanova method [9]. MDA in the muscles was determined by the reaction with tiabarbituric acid (TBA) at a high temperature in the acidic media. The aliquot of the muscles tissue was frozen in a porcelain jar with the help of liquid nitrogen and carefully contused. The obtained powder was dissolved in the buffered solution $(\mathrm{pH} \mathrm{7,4)}$ and after adding trichloroacetic acid was centrifugated for $15 \mathrm{~min}$ at $5000 \mathrm{rev} / \mathrm{min}$ in OPN-8 centrifuge (produced by Labtech, Russia). Supernatant was mixed with TBA and placed into the boiling water bath for 10 minutes. The optical density was determined after cooling on spectrophotometer at the $532 \mathrm{~nm}$ wavelength against reagent control [9].

Indicators of the intensity of lipoperoxidation systems (ПОЛ) and antioxidant equilibrium (AOE) was assessed in the blood of control and sensibilized mice. Unfortunately, we did not have the opportunity to conduct this research in homogenate muscles for the reasons of their very small size. We determined catalase activity in blood erythrocytes using ammonium molybdate at the $410 \mathrm{~nm}$ wave length and peroxidase, in the staining reaction with indigo carmine. We determined the level of ceruleoplasmin in the blood serum, using the reactant of hydrochloric paraphenylenediamine, nitrite ions, with the help of Griss reagent. The overall antioxidative activity antioxidative activity (AOA) was evaluated in the yoke lipoproteids obtained by mixing chicken yoke 1:50 with the phosphate buffer ( $\mathrm{pH}$ 7.4). This model contained lipid protein complexes, corresponding in terms of the composition of low density lipoproteids (LDLP) and very low density lipoproteids (VLDL). Ferriferrous sulphate injection speeds up the oxidation of the fatty acids which are part of lipids and the formation of Lipid peroxides. The intensity of lipids peroxidation was determined by the content of lipids hydroperoxides spectrophotometrically at the $232 \mathrm{~nm}$ wave length of TBA-interacting lipid peroxides, the MDA in the serum and homogenate muscles during the reaction with thiobarbituric acid [9].

The obtained results were statistically analyzed Statistical analysis included parametric and non-parametric criteria. The difference was considered significant when probability (p) was $<0.05$. The results were expressed as $X \pm S x(n)$, where $X-$ arithmetical mean value, $\mathrm{Sx}$ - average error mean, $\mathrm{n}$ - number of observations.

The obtained results have been processed statistically (BIOSTATISTICA) $[10 ; 11 ; 12]$. For data analysis parametric and non-parametric criteria have been used. If the probability level (p) did not exceed 0,05, the difference was considered authentic. The results were presented as $\mathrm{X} \pm \mathrm{Sx}(\mathrm{n})$, where $\mathrm{X}$ is arithmetic mean value, $\mathrm{Sx}$ is mean error, $\mathrm{n}$ is the number of observations.

\section{RESULTS}

$\mathrm{CC}$ in sub-maximal concentration $\left(7 \times 10^{-4} \mathrm{~mol}\right)$ elicited contraction $\mathrm{m}$. EDL non-sensibilized mouse with the force $76.6 \pm 6.1 \mathrm{mg}$ and speed $14.3 \pm 1.6 \mathrm{mg} / \mathrm{sec}$. At PS, the strength of the "fast" muscles decreased to $61.9 \pm 12.2 \mathrm{mg}$, the speed practically did not change - $13.6 \pm 4.1 \mathrm{mg} / \mathrm{sec}$. Contraction m.edl of non-sensibilized mouse in connection with $\mathrm{CC}$ maximum concentration $\left(4 \times 10^{-3} \mathrm{~mol}\right)$ had the speed of $11,15 \pm 1,97 \mathrm{mg} / \mathrm{sec}$. At PS this indicator lowered to $4,62 \pm 1,68 \mathrm{mg} / \mathrm{sec}(\mathrm{p}<0,05)$.

$\mathrm{CC}$ in sub-maximal concentration $\left(5 \times 10^{-4} \mathrm{~mol}\right)$ in the m.soleus of a non-sensibilized mouse elicited a contraction with the strength of $237,8 \pm 20,6 \mathrm{mg}$ and the speed $13,1 \pm 1,0$ $\mathrm{mg} / \mathrm{sec}$. PS increased the force $353,2 \pm 23,1 \mathrm{mg}(\mathrm{p}<0,01)$ and the speed $16,6 \pm 1,5 \mathrm{mg} / \mathrm{sec}$ of the slow muscle contraction. Maximum $\mathrm{CC}$ concentration $\left(2 \times 10^{-3} \mathrm{~mol}\right)$ elicited the slow 
muscle contraction in a non-sensibilized mouse with the speed of $24,64 \pm 3,65 \mathrm{mg} / \mathrm{sec}$. PS lowered this indicator to $13,44 \pm 2,43$ $\mathrm{mg} / \mathrm{sec}$. $(\mathrm{p}<0,05)$.

m.edl contraction force as a response to the maximal concentration of agonist $(4 \times 10-3 \mathrm{M})$ and $\mathrm{KCl}(250 \mathrm{mmol} / \mathrm{l}) \mathrm{had}$ the following values in the control group: $103,83 \pm 15,70 \mathrm{mg}$ and $136,69 \pm 6,73 \mathrm{mg}\left(\mathrm{P}_{\mathrm{KX} \max } / \mathrm{P}_{\mathrm{KClmax}}-75,9 \%\right)$ and in case of PS changed correspondingly 52,13 $\pm 14,66 \mathrm{mg}(\mathrm{p}<0,05)$ and $142,72 \pm 23,83 \mathrm{mg}\left(\mathrm{P}_{K X \max } / \mathrm{P}_{\mathrm{KClmax}}-36,5 \%\right)$, i.e., $\mathrm{P}_{K X \max } / \mathrm{P}_{K C \max }$ indicator in case of PS decreased to $48,1 \%$ in comparison with the control group.

For m.soleus contraction force for the agonist in maximum concentration $\left(2 \times 10^{-3} \mathrm{~mol}\right)$ and $\mathrm{KCl}(150 \mathrm{mmol} / \mathrm{l})(\mathrm{mM})$ in the control group had the values: $322,32 \pm 30,18 \mathrm{mg}$ and $643,23 \pm 69,59 \mathrm{mg}\left(\mathrm{P}_{\mathrm{KX} \max } / \mathrm{P}_{\mathrm{KClmax}}-50,1 \%\right)$ in case of PS changed correspondingly to $475,14 \pm 52,66 \mathrm{mg}(\mathrm{p}<0,05)$ and $1470,49 \pm 186,05 \mathrm{mg}(\mathrm{p}<0,01)\left(\mathrm{P}_{\mathrm{KXmax}} / \mathrm{P}_{\mathrm{KClmax}}-32,3 \%\right)$, i.e., $\mathrm{P}_{\mathrm{KXmax}} / \mathrm{P}_{\mathrm{KClmax}}$ indicator in case of PS decreased to $64,5 \%$ in comparison with the control group.

The level of MDA in the serum with PS decreased from $2,65 \pm 0,88$ to $1,65 \pm 0,4 \mathrm{umol} / 1(\mathrm{n}=8, \mathrm{p}<0,05)$. MDA decreased in m.soleus tissue from $237,36 \pm 73,67 \mathrm{mkmol} / \mathrm{kg}$ to $119,46 \pm 24,65 \mathrm{mkmol} / \mathrm{kg} \quad(\mathrm{p}<0,05)$, in m.edl, MDA insignificantly increased from $111,02 \pm 25,61 \mathrm{mkmol} / \mathrm{kg}$ to $127,99 \pm 8,93 \mathrm{mkmol} / \mathrm{kg}$ ( $\mathrm{mkM} / \mathrm{kg})$.

The indicators of antioxidant enzyme activity and the content of the lipid peroxygenation products in the blood of intact and sensibilized mice were presented in the Table 1.

The indicators of antioxidant enzyme activity and the content of the lipid peroxygenation products in the blood of intact and sensibilized mice

\begin{tabular}{|c|c|c|c|}
\hline $\begin{array}{c}\text { Indicators/ } \\
\text { animals groups }\end{array}$ & Control & $\begin{array}{c}\text { Sensibili- } \\
\text { zation }\end{array}$ & $\pm \%$ \\
\hline $\begin{array}{c}\text { Lipides' } \\
\text { Hydroperoxide } \\
\text { lipides } \\
\text { (u/ml) }\end{array}$ & $\begin{array}{c} \pm, 97 \\
\text { Malonyldialdeh }\end{array}$ & $6,62^{*}$ & $+66,8 \%$ \\
yde (mkmol / ). & $\pm 0,54$ & \\
\hline NO (mmol/1) & 24,62 & 27,82 & $+13,0 \%$ \\
& $\pm 2,23$ & $\pm 1,28$ & \\
\hline Summary & 43,51 & $30,19 *$ & $-69,4 \%$ \\
AOA (\%) & $\pm 2,88$ & $\pm 3,96$ & \\
\hline COD (c.u.) & 0,36 & $0,80 * *$ & $+122,2 \%$ \\
& $\pm 0,10$ & $\pm 0,07$ & \\
\hline Catalase (x 10 & 762070,50 & $219780,00^{* *}$ & $-71,2 \%$ \\
mkcatal/1) & $\pm 15409,64$ & $*$ & \\
& & $\pm 9121,32$ & \\
\hline Peroxydase & 85,66 & $126,71 *$ & $+47,9 \%$ \\
(int.u.) & $\pm 12,56$ & $\pm 10,09$ & \\
\hline Caeruloplasmin & 43,25 & $21,04 * * *$ & $-48,6 \%$ \\
(mmol/l) & $\pm 0,80$ & $\pm 1,90$ & \\
\hline
\end{tabular}

Note: $\mathrm{n}-$ number of animals; * $\mathrm{P}<0,05$; ** $\mathrm{P}<0,01$; *** $\mathrm{P}<0,001$.

\section{DISCUSSIONS}

Experiments results demonstrate that adaptation processes actively go on in skeletal muscles during the allergic modification. This happens both due to the modification of their functional properties and also due to the capacity to support intracellular homeostasis on the level corresponding to the body's demands. It happens differently in various muscles.

It has been demonstrated on the isolated mouse SM that in case of PS both muscles change their contraction mode when $\mathrm{CC}$ is used. Contraction speed was suppressed. The change of the contraction force characteristics had the multi-vector character. They decreased in the fast muscle's case and increased in the slow muscle. Hypothetically, PS might touch SM surface membrane, including a postsynaptic one, EMC mechanisms or the contractile proteins' system. The aggregate of the discovered changes demonstrates that various stages of the contractile process are involved into the adaptation mechanisms. Speed decrease provides the evidence that in case of PS ipsidirectional changes of the EMC system occur in all muscles. The differences in the force's change which characterize cholin-related processes of FM excitation have multi-vector character in fast and slow mucles.

The muscle strength is in the direct dependency from the sensitivity to cholinomimetic in case of CC-related contraction. It is evident that the reasons of the changes discovered by us are related both to the original differences of the morpho-functional status of the objects of research $[1 ; 2]$, and to the mechanisms of its dynamics during the allergic modification process.

Earlier we have demonstrated that ATP takes part in the adaptation mechanisms of slow (m.soleus) mouse muscles in case of PS [13; 14]. It is evident that under these conditions the change in the $\mathrm{P} 2$ receptors sensitivity of the myoneural junction presynaptic membrane leads to the adequate change in the current of acetylcholine non-quant secretion $(\mathrm{Ax})$, which has impact upon the sensitivity of the postsynaptic membrane to cholinomimetic. We can assume the existence of a few mechanisms $[15 ; 16 ; 17]$ in order to explain these laboratory effects. Firstly, the increase in the level of ATP in the media, including muscular tissues, elicits desencitization of purine receptors (assumably $\mathrm{P} 2 \mathrm{Y}$ ) of presynaptic membrane, which decreases their sensitivity to exogenic ATP, introduced into the basin during the experiment. For this reason in the slow muscles dynamics of the non-quantum secretion $\mathrm{Ax}$ and muscles contraction force in response to cholinomimetic to exogenic ATP in PS conditions is different from the same characteristics in the control group $[18 ; 19]$. Exogenic ATP when it's added into a basin almost completely eliminates the non-quantized Ax output $[20 ; 21]$ in intact muscles in our experimental models. Maximum ATP affect was achieved by the choice of the appropriate concentration and the time of the substance exposition for better visualization, during which the stock of the possibilities for the realization of the given biological mechanism shortens significantly (almost completely). In PS conditions, the presence of endogenic ATP, 
which appears in muscular tissue during the allergic response generation partially overlaps with the potential for decreasing non-quantized Ax secretion and adding exogenic ATP into a basin then does not lead to the desired result. Of course, we can not exclude some other mechanisms of the change in the sensitivity of postsynaptic receptors to the agonist.

Thus, according to our results, ATP-dependent mechanisms of regulating their sensitivity to Ax cause the development of resistance both to the long-term external loads, and also experimental allergy in slow phasal muscles. If an organism is whole, these processes are ergogenic if there is continued physical activity. We can suppose that similar mechanisms determine the decrease in the respiration muscles fatigue in case of hypoxia which appears during functional insufficiency of the external respiration systems.

We obtained contractile responses to various humoral agents in vitro in a mouse m.edl and m.soleus. Sub-maximum and maximum concentration have been determined for both contraction initiators for both muscles. The analysis of contraction to $\mathrm{CC}$ allows assessing not only choline-related excitation processes, but also the next FM work stages [14]. Potassium contracture is a convenient test for studying EMC processes [9]. The use of $\mathrm{P}_{\mathrm{KXmax}} / \mathrm{P}_{\mathrm{KClmax}}$ indicator (the ratio of contraction maximum force to various humoral initiators) gives us the opportunity to clarify individual stages determined by EMC intracellular mechanisms separating them from the process of muscular membrane excitement.

Significant differences in the characteristics of contractile responses of the fast and slow muscles of the mouse shin to $\mathrm{CC}$ and $\mathrm{KCl}$ allows to make the following assumption. The variability of $\mathrm{CC}$ contractions has a morphological basis. The difference in force is directly related to the fibers' composition. Mouse's m.soleus contains $50-60 \%$ of slow fibers and m.edl by $97-100 \%$ consists of fast muscles [22]. The sizes of the endplate in FM of the slow muscles (m.soleus) is 3 times longer than in the FM of the fast muscle (m.edl). Correspondingly, the greatest contraction force of slow muscles while using $\mathrm{CC}$ is the consequence of its higher sensitivity to the cholinomimetic and is conditioned by a large number of cholinreceptors (CR) in the synapse area.

The research literature demonstrates that the changes in FM during sensibilization involve the surface membrane [1], EMC mechanisms or the contractile proteins system. Correspondingly, the PS capacity to change the constrictive properties of mouse's SM have ambiguous nature. The different direction of the contraction force dynamics vector in response to $\mathrm{CC}$ in $\mathrm{m}$.soleus and $\mathrm{m}$.edl point to the fact that the difference in the functional changes of two muscles in PS are provided, first of all, by the cholin-related processes of FM membrane excitation. The suppression of speed of $\mathrm{CC}$ responses for both muscles determines EMC mechanisms as participants of SM adaptation process in conditions of PS.

Dynamics of the potassium contracture speed give evidence of the unclear capacity of $\mathrm{Ca} 2+$-dependent mechanisms in the muscles with various phenotypes to adaptation in PS conditions which is confirmed by the analysis based on the $\mathrm{P}_{\mathrm{KX} \max } / \mathrm{P}_{\mathrm{KClmax}}$ ratio. In both cases it decreases, however, for fast muscles it is more expressed (up to $48,1 \%$ from the original value) than for the slow muscle (to $64,5 \%$ ). Thus, the multi-vector impact of PS to the strength of CCelicited contraction and the contraction speed to $\mathrm{KCl}$ in fast and slow muscles are adaptation expressions which determines the plasticity of these muscles. The further study of SM adaptation mechanisms in case of allergy will reveal the new methods for correcting these fictions and mark out the medicinal impact strategy taking into account the fiber content of the specific muscles.

The obtained results confirm the assumption that the capacity for adaptation in the transverse stripe muscles in case of allergy are provided not only by the postsynaptic membrane and the following electromechanical coupling stages. In particular, the dependency of the work of the nervous system in the histogenesis process on the trophic and humoral factors allows us to assume that sceletal muscles take part in adapting a few receptors to the conditions of allergy. In particular, the local involvement of muscarinic acetylcholine and adenosine autoreceptor and corresponding mediators [23;24].

We also plan to research the dynamics of the presynaptic formation functions in different types of transversal stripe muscles in the specified experimental conditions. To determine the precise role of this myoneural junction, we plan to conduct a few experiments with the abovementioned muscles in vitro in the conditions of their direct and non-direct electrical stimulation.

The violation of PS conditions in the oxidant and antioxidant equilibrium systems, which is one of the reasons of the discovered changes, can have impact upon the secondary messengers' system through adenosine triphosphate [21] and to regulate the contraction of transversal muscles in this way.

One of the ways to sustain homeostasis in tissues and organs is the interaction of oxidant and antioxidant equilibrium systems. Certain elements of the abovementioned systems play a part in the discovered changes. To prove that this assumption is true, we can point to the correlation of the MDA level with ATP syntheses activity. These results have been obtained on a mouse's heart muscle [23].

Even though the heart muscle is transversal, but it differs from the skeletal one both in terms of its functions and its morphological characteristics. However, the research we have planned (searching for differences in the dynamics of ATPsynthase activity for sceletal and breathing muscles of both sensibilized and intact mice through biochemical and physiological methods will allow to fuller revel the muscular system adaptation mechanisms in conditions of allergy.

MDA is an oxidative stress marker $[7 ; 8]$ and it determines the condition of a few membrane [24] and miochondrial [25] proteins and, as a consequence, the dynamics of electromechanical coupling mechanisms in locomotor muscles during the body's allergic modification.

Comparison of the dynamics of the contraction force with the change in the MDA level confirms the PS capacity to change intracellular homeostasis mechanisms in various SM. The increase of the slow muscles force correlates with the decrease in MDA, which reflects the work of corresponding compensation mechanisms when the FM membrane sensitivity to the agonist increases. Similar reasons can be pointed out in 
case of the next EMC stages deviation. The decrease of force for the fast muscle is not related to the MDA level [26]. Aldehyde dynamics in case of PS in a slow muscle is indirectly a reason for changes, both on the membrane and also in its fiber membrane cytoplasm. ATP-dependent mechanisms regulate SM contraction SM by influencing the intracellular mediators' system $[3 ; 5 ; 8]$. This is elicited by the violation of the balance of oxidant and antioxidant equilibrium systems. This assumption is confirmed by the correlation of MDA dynamics with ATP-synthase activity demonstrated by C.S. Yarian et all. [23] on transversal (cardiac and sceletal) muscles in mice.

In particular, the authors in the process of research elicitied the changes in mitochondrial proteins, which during the aging processes express post-translational oxidative modifications. The enzymes which change their activity after MDA impact were determined in mitochondrias taken from the heart and sceletal muscles of the hind leg of 6,16 and 24-month mice via immunodetection method. The authors studied a number of proteins as supposed targets among which only ATP-synthase and aconitase significantly decreased their activity with age.

If the data related to correlation of the dynamics of contractile properties of sceletal muscles and MDA level confirm the assumption made earlier about the mechanisms of adaptive possibilities' changes for fast and slow sceletal muscles in the allergy conditions, then the results of studying the antioxidant ferments activity and lipoperoxidation products in the blood are not so clear-cut and their interpretation requires the conducting of further research.

Besides, we consider highly informative the results of prospective research with determination of ATP-synth activity in mouse's fast and slow muscles in case of allergy. Evidently, the dynamics of this ferment's intensity of work should coincide in terms of vector of changes to conractile properties of muscles under the exogenic ATP influence, which, in its own turn, evidently, should have a close dependency on the condition of oxidant and antioxidant equilibrium systems.

\section{CONCLUSION}

Mechanisms of locomotor muscles plasticity in PS conditions are determined by the work of EMC mechanisms, located on choline-initiated postsynaptic membrane and also in the fiber membrane (FM) cytoplasm. The change in the postsynapse sensitivity to Ax in various types of muscles are the reason of multi-vector dynamics of the contraction while using cholinomymetic. Besides, the contraction force of various SM in case of PS correlates with the change of one of the key lipoperoxidation markers, such as MDA. In slow muscles, the contraction force increase coincides with the lowering of the dialdehyde level. A fast muscle turns out to be more stable to oxidative stress which evidently is achieved by the work of compensatory mechanisms and is expressed by very insignificant changes in MDA dynamics.

\section{REFERENCES}

[1] A.D. Ado, N.V. Stomakhina, L.M. Tuluevskaya, and V.N. Fedoseeva, "Protein spectra and phospholipid composition of membranes enriched with cholinergic receptors from skeletal muscle of rats under sensitization", in Bulletin experimental biololgical medicine, 1984, 99 (7), pp. 84-86. (in Russian)

[2] I.S. Gushchin, A.I. Zebreva, and N.L. Bogush, "An experimental model for the development and evaluation of methods for controlling immediate allergies", in Patological physiologic and experimental therapy, 1986, 4, pp. 18-23. (in Russian)

[3] A.Yu. Teplov, A.M. Farkhutdinov, and S.N. Grishin, in "Possible mechanisms for changing the contractile function of isolated striated muscle of the mouse during allergic restructuring of the body", in Preventive and clinical medicine (Bulletin of the St. Petersburg State Medical Academy named after I.I. Mechnikov), 2010, 1 (34), pp. 105-110. (in Russian)

[4] A.U. Ziganshin, "P2 receptors as promising targets for future drugs", in Kazan medical journal, 2016, 97 (1), pp. 135-141. (in Russian)

[5] A.Yu. Teplov, "The effect of protein sensitization on the contractile properties of "fast" and "slow" mouse muscles in vitro", in Nizhny Novgorod Medical Journal, 2006, 3, pp. 21-24. (in Russian)

[6] S.N. Grishin, and A.U. Ziganshin, "The role of purines in neuromuscular transmission", in Biological membranes, pp. Journal of Membrane and Cell Biology, 2013, 30 (4), pp. 243. (in Russian)

[7] C. Espinosa-Diez, V. Miguel, D. Mennerich, T. Kietzmann, P. Sánchez-Pérez, S. Cadenas, and S. Lamas, "Antioxidant responses and cellular adjustments to oxidative stress", in Redox Biol, 29015, 6, pp.183-97. https, pp.//doi.org/10.1016 j.redox.2015.07.008.

[8] O.V. Lushchak, M. Piroddi, F. Galli, V.I. Lushchak, "Aconitase post-translational modification as a key in linkage between Krebs cycle, iron homeostasis, redox signaling, and metabolism of reactive oxygen species", in Redox Rep., 2014, 19(1), pp. 8-15. https, pp.//doi.org/ 10.11791351000213 Y.0000000073.

[9] T.I. Rakhmanova, L.V. Matasova, A.V. Semenikhina, O.A. Safonova, A.V. Makeeva, and T.N. Popova. Methods for the oxidative status evaluation. Voronezh: VGU Publishing House, 2009, pp.1.64 (in Russian).

[10] S.A. Glantz, Primer of Biostatistics. McGraw Hill: Health Professions Division, 2012.

[11] E.Ch. Hayden, "Biostatistics: Revealing analysis". Nature. 2012, 482 (7384), pp. 263-265. doi:10.1038/nj7384-263a

[12] J.M. Utts, Seeing through statistic. Belmont, CA: Thomson, Brooks/Cole, 2005

[13] A.Yu. Teplov, A.M. Farkhutdinov, S.N. Grishin, and M.M. Minnebaev, "Possible mechanisms of the influence of protein sensitization on the functional properties of isolated m.soleus and m.edl mice", in Bulletin of Experimental Biology and Medicine, 2010, 150 (9), pp. 262-265. (in Russian)

[14] A. Teplov, S. Grishin, and M. Mukhamedyarov, "Ovalbumininduced sensitization affects non-quantal acetylcholine release from motor nerve terminals and alters contractility of skeletal muscles in mice", in Exp Physiol. 2009, 94(2), pp. 264-268. https, pp.//doi.org/10.1113 expphysiol.2008.045740.

[15] G. Burnstock, "Historical review, pp. ATP as a neurotransmitter", in Trends Pharmacol Science, 2006, 27 (3), pp. 166-176.

[16] G. Burnstock, "Physiology and pathophysiology of purinergic neurotransmission", in Physiol Rev. 2007, 87(2), pp. 659-797.

[17] G. Burnstock, "Purinergic signalling, pp. pathophysiology and therapeutic potential". Keio Journal Med, 2013, 62(3), pp. 63-73.

[18] L. Nadal, N. Garcia, E. Hurtado, A. Simó, M. Tomàs, M.A. Lanuza, V. Cilleros, and J. Tomàs, "Presynaptic Muscarinic 
Acetylcholine Receptors and TrkB Receptor Cooperate in the Elimination of Redundant Motor Nerve Terminals during Development". Front Aging Neurosci. 2017, 9, pp. 24. https, pp.//doi.org/10.3389 fnagi.2017.00024.

[19] L. Nadal, N. Garcia, E. Hurtado, A. Simó, M. Tomàs, M.A. Lanuza, V. Cilleros, and J. Tomàs, "Synergistic Action of Presynaptic Muscarinic Acetylcholine Receptors and Adenosine Receptors in Developmental Axonal Competition at the Neuromuscular Junction". Dev Neurosci. 2016, 38(6), pp. 407-419. https, pp.//doi.org/10.1159 000458437

[20] J. Tomàs, N. Garcia, M.A. Lanuza, M.M. Santafé , M. Tomàs, L. Nadal, E. Hurtado, A. Simó, V and. Cilleros, "Presynaptic Membrane Receptors Modulate ACh Release, Axonal Competition and Synapse Elimination during Neuromuscular Junction Development", in Front Mol Neurosci. 2017, 16 (10), pp. 132. https, pp.//doi.org/10.3389 fnmol.2017.00132.

[21] J. Tomàs, N. Garcia, M.A. Lanuza, M.M. Santafé , M. Tomàs, L. Nadal, E. Hurtado, A. Simó, V and. Cilleros, "Membrane Receptor-Induced Changes of the Protein Kinases A and C Activity May Play a Leading Role in Promoting Developmental Synapse Elimination at the Neuromuscular Junction", in Front Mol Neurosci. 2017, 10, pp. 255. https, pp.//doi.org/10.3389 fnmol.2017.00255.

[22] J.A. Florendo, J.F. Reger, and P.K. Law, “ Electrophysiologic differences between mouse extensor digitorum longus and soleus", in Experimental Neurology, 1983, 82(2), pp. 404-412.

[23] C.S. Yarian, I. Rebrin, and R.S. Sohal, "Aconitase and ATP synthase are targets of malondialdehyde modification and undergo an age-related decrease in activity in mouse heart mitochondria", in Biochem Biophys Res Commun. 2005, 330(1), pp. 151-156.

[24] C. Kang, L. Li Ji, "Role of PGC-1 $\alpha$ signaling in skeletal muscle health and disease", in Ann N Y Acad Sci. 2012, 1271, pp. 110-117. https, pp.//doi.org/10.1111 j.1749-6632.2012.06738.x.

[25] S. Miura, S.I. Saitoh, T. Kokubun, T. Owada, H. Yamauchi, H. Machii, and Y. Takeishi, "Mitochondrial-Targeted Antioxidant Maintains Blood Flow, Mitochondrial Function, and Redox Balance in Old Mice Following Prolonged Limb Ischemia". Int J Mol Sci., 2017, 4; 18(9). pii, pp. E1897. https, pp.//doi.org/ 10.3390 ijms18091897.

[26] Kh. Zennir, A. Allahem, S. Boulaaras, B. Cherif, "Develop Mathematical Models to Control the Diffusion of Antibiotic Resistant Bacteria to Avoid a Serious Public Health Hazard", WSEAS Transactions on Mathematics, 2019, 18, pp. 97-104.

\section{Creative Commons Attribution License 4.0 (Attribution 4.0 International, CC BY 4.0)}

This article is published under the terms of the Creative Commons Attribution License 4.0 https://creativecommons.org/licenses/by/4.0/deed.en_US 